\title{
Analysis of Seismological and Tsunami Data from the 1993 Guam Earthquake
}

\author{
Yuichiro TANIOKA, ${ }^{1}$ Kenji SATAKE, ${ }^{1}$ and LARry RufF ${ }^{1}$
}

\begin{abstract}
The fault parameters of the Guam earthquake of August 8, 1993 are estimated from seismological analyses, and the possibility of identifying the actual fault plane from tsunami waveforms is tested. The Centroid Moment Tensor solution of long-period surface waves shows one nodal plane shallowly dipping to the north and the other nodal plane steeply dipping to the south. The seismic moment is $3.5 \times 10^{20} \mathrm{Nm}$ and the corresponding moment magnitude is 7.7. The Moment Tensor Rate Function inversion of $P$ waves also yields a similar focal mechanism and seismic moment. The point source depth is estimated as $40-50 \mathrm{~km}$.

This earthquake generated tsunamis that propagated toward the Japanese coast along the IzuBonin-Mariana ridge system. The tsunamis are recorded on ocean bottom pressure gauges and tide gauges. Numerical computation of tsunamis shows that the computed waveforms from the two possible fault planes match well with the observed tsunami waveforms. The numerical computation also shows that the tsunami waveforms at Guam Island, just above the fault, should contain useful information regarding the identification of the actual fault plane. However, the current sampling rate of the tide gauges is so small that the records cannot help the identification.
\end{abstract}

Key words: Tsunamis, the 1993 Guam earthquake, fault plane.

\section{Introduction}

A large earthquake $\left(M_{s}=8.0\right)$ occurred south of Guam Island on August 8, 1993. The National Earthquake Information Center (NEIC) Preliminary Determination of Epicenters (PDE) provides the following estimates: origin time, 08:34:24.93 GMT; epicenter, $12.982^{\circ} \mathrm{N}, 144.801^{\circ} \mathrm{E}$; depth $59 \mathrm{~km}$; magnitude, $M_{s} 8.0$. The location of the main shock is shown in Figure 1. This is the largest earthquake ever recorded in the Mariana Arc region. This earthquake generated a moderatesize tsunami that was observed on tide gauge stations in Guam and Japan and ocean bottom pressure gauge stations near Japan. A student in Guam, Jody Flores, conducted a survey of local residents and collected descriptive accounts (SIGRIST, 1995).

Department of Geological Sciences, University of Michigan, Ann Arbor, MI 48109-1063, U.S.A. 


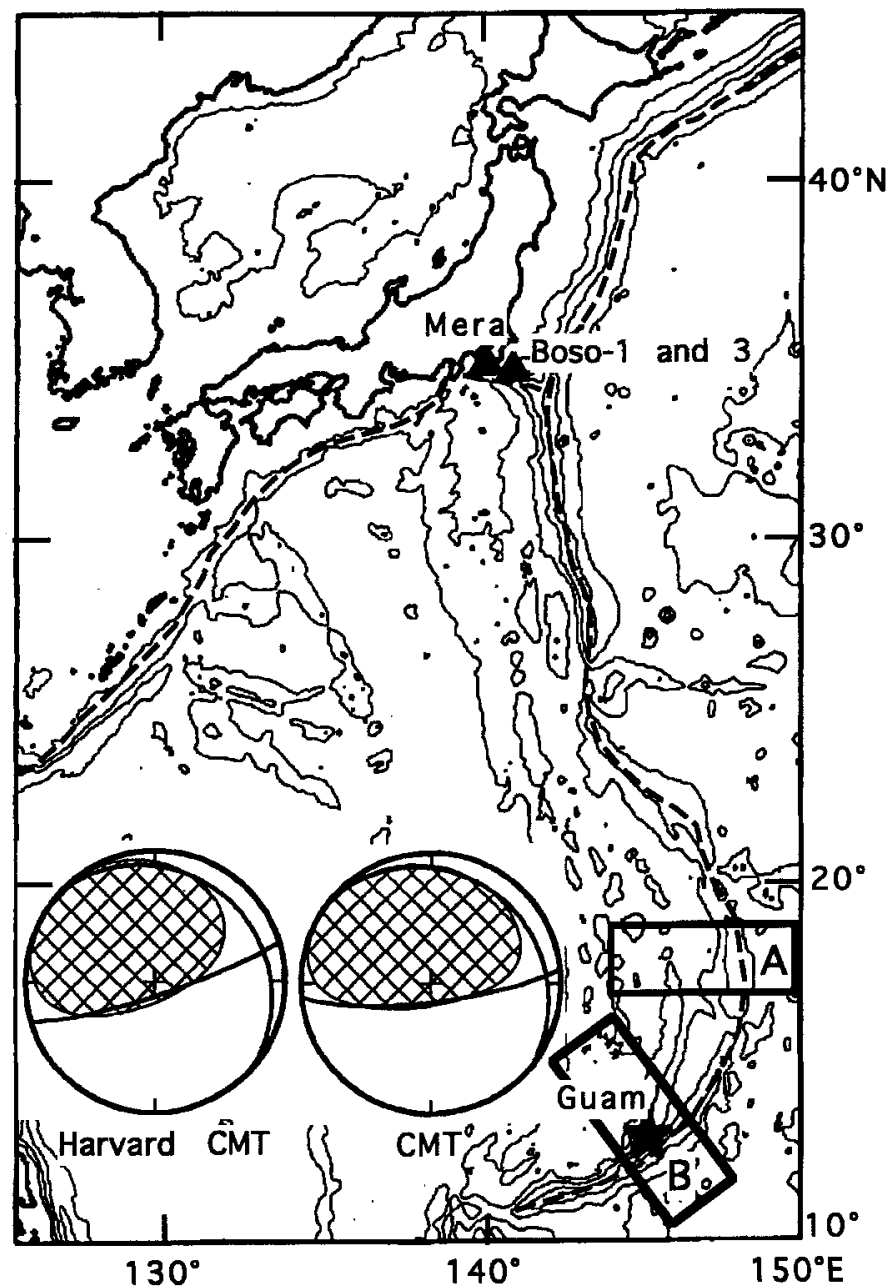

Figure 1

Topography map around the Izu-Bonin-Mariana region with the Harvard and our CMT solutions of the 1993 Guam earthquake. The star shows the epicenter of the Guam earthquake. The triangles show the location of tide gauge and ocean bottom pressure gauge stations. The dashed lines show the plate boundaries in this region. Two boxes represent the locations and limits of the vertical cross section of seismicity in Figure 2.

The largest earthquake previously known in this region occurred on April 5, $1990\left(M_{s}=7.5\right)$ with a normal fault mechanism in the outer-rise region (YosHIDA et al., 1992). The Mariana trench is characterized as a weakly coupled subduction zone where no great thrust event has ever occurred (UYEDA and KANAMORI, 1979). The epicentral data suggest that the Guam earthquake occurred in the subduction zone, not in the outer-rise region. Determination of the source process of this earthquake is very important to understand the characteristics of subduction in the Mariana Arc. 


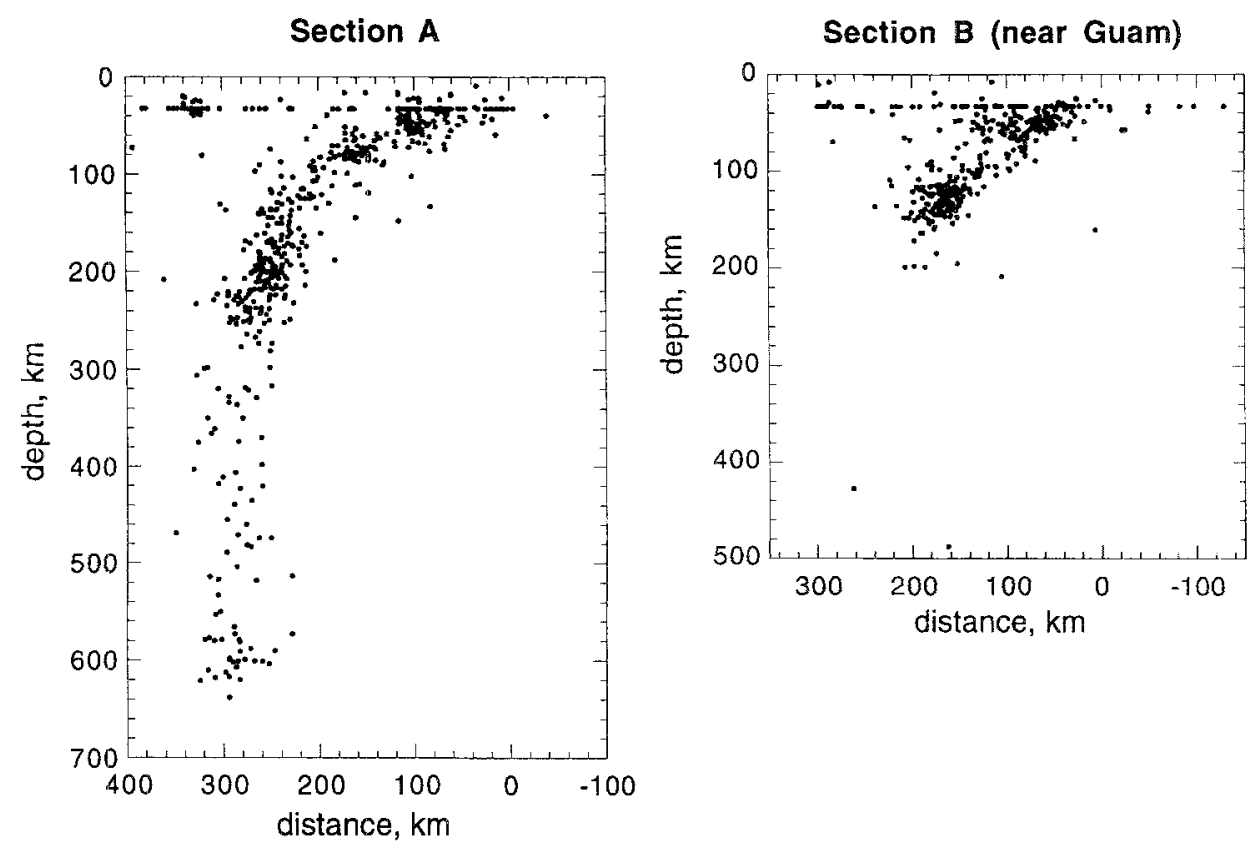

Figure 2

The vertical cross section of the seismicity in sections A and B (see Figure 1 for location). The hypocentral data from 1928 to 1987 are plotted from the NEIC catalog.

In this paper, we use seismic surface waves and body waves to estimate the fault parameters of this earthquake. We further discuss the importance of the identification of the actual fault plane of this earthquake. We then numerically compute tsunami waveforms to test whether we can identify the fault plane from the tsunami waveforms recorded at tide gauge stations. We also examine the bathymetric effect on the tsunami propagation.

\section{Seismological Analyses}

\section{a) Seismicity in the Mariana Region}

Figure 2 illustrates two vertical cross sections of seismicity in the Mariana region, constructed from the NEIC PDE catalog of hypocentral parameters. Section A (see Figure I for the location) shows that the seismic activity is continuously distributed to a depth of $650 \mathrm{~km}$ and the distribution below a depth of $200 \mathrm{~km}$ is nearly vertical. However, section B, which includes the hypocenter of the 1993 Guam earthquake, shows seismic activity to a depth of only $200 \mathrm{~km}$. Also notice that the apparent dip of the slab suggested from the earthquake distribution 
Table 1

Source parameters of the 1993 Guam earthquake

\begin{tabular}{lcc}
\hline & CMT solution & MTRF solution \\
\hline strike & $310^{\circ} / 84^{\circ}$ & $238^{\circ} / 67^{\circ}$ \\
dip & $17^{\circ} / 78^{\circ}$ & $24^{\circ} / 67^{\circ}$ \\
rake & $135^{\circ} / 78^{\circ}$ & $82^{\circ} / 94^{\circ}$ \\
$\mathrm{M}_{\mathrm{o}}$ & $3.5 \times 10^{20} \mathrm{Nm}$ & $2.7 \times 10^{20} \mathrm{Nm}$ \\
$\mathrm{M}_{\mathrm{w}}$ & 7.7 & 7.6 \\
depth & $50 \mathrm{~km}$ (fixed) & $40-50 \mathrm{~km}$ \\
duration & - & $32 \mathrm{sec}$ \\
\hline
\end{tabular}

between 50 and $150 \mathrm{~km}$ is $40^{\circ}$. This indicates that the geometry of the slab changes between sections A and B. Further, the characteristics of subduction in section B may be different from that in section $\mathrm{A}$, which is defined as a weakly coupled subduction zone (UYEDA and KANAMORI, 1979).

\section{b) Surface Wave Analysis}

We performed Centroid Moment Tensor (CMT) inversion (DzIEwONSKI et al., 1981; FUKUSHIMA et al., 1989) using long-period surface waveforms recorded at 12 Incorporated Research Institutions for Seismology (IRIS) network stations (ANMO, CCM, COL, CTAO, HRV, KIP, MAJO, PAB, PAS, RAR, ANTO, and CHTO). The result of this computation is summarized in Table 1 . The $T$ axis is $-3.2 \times 10^{20} \mathrm{Nm}$ (plunge $55^{\circ}$, azimuth $339^{\circ}$ ), the $P$ axis is $3.8 \times 10^{20} \mathrm{Nm}$ (plunge $32^{\circ}$, azimuth $184^{\circ}$ ), and the $N$ axis is $-0.6 \times 10^{20} \mathrm{Nm}$. The seismic moment is estimated as $3.5 \times 10^{20} \mathrm{Nm}$ and the corresponding moment magnitude is 7.7 . The focal mechanism has one nodal plane dipping shallowly to the north (strike $310^{\circ}$, $\operatorname{dip} 17^{\circ}$, rake $135^{\circ}$ ) and the other steeply dipping to the south (strike $84^{\circ}$, dip $78^{\circ}$, rake $78^{\circ}$ ) (Figure 1). Figure 1 also shows the focal mechanism from the Harvard CMT which is similar to our estimate. The slip directions from these mechanisms are close to the direction perpendicular to the Mariana trench.

\section{c) Body Wave Analysis}

We performed Moment Tensor Rate Function (MTRF) inversion (RUFF and Miller, 1994) using broadband $P$ waves recorded at 9 stations, 8 IRIS network stations (ANMO, CCM, KONO, OBN, PAS, KIP, ARV, COL) and the University of Michigan station (AAM). We used the first $90 \mathrm{~s}$ of the $P$ wave, filtered with a $2 \mathrm{~s}$ duration triangle. The MTRFs are sampled at $2 \mathrm{~s}$ intervals. We first performed the MTRF inversion to determine the best depth. The average $P$-wave velocity from the surface to the earthquake source (20-100 km) should be between the crustal $P$ - 


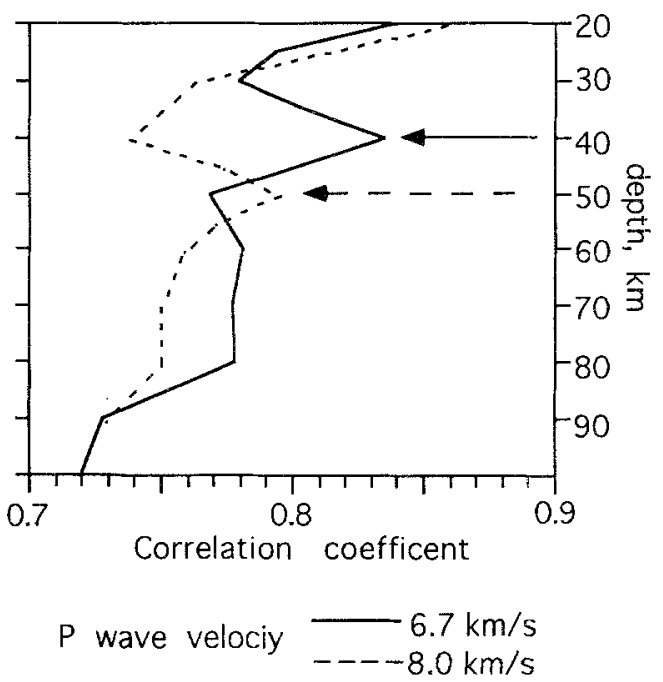

Figure 3

The correlation coefficient between the observed and synthetic seismograms are plotted for different point source depths. The solid line is for $P$-wave velocity of $6.7 \mathrm{~km} / \mathrm{s}$ and the dashed line is for $P$-wave velocity of $8.0 \mathrm{~km} / \mathrm{s}$.

wave velocity, $6.7 \mathrm{~km} / \mathrm{s}$, and the uppermost mantle $P$-wave velocity, $8.0 \mathrm{~km} / \mathrm{s}$. We therefore performed the inversion using the different velocities, $6.7 \mathrm{~km} / \mathrm{s}$ and $8.0 \mathrm{~km} / \mathrm{s}$. Figure 3 shows the correlation coefficient between the synthetic and observed seismograms as a function of source depth. The best depth is $40 \mathrm{~km}$ and $50 \mathrm{~km}$ for the assumed $P$-wave velocity of $6.7 \mathrm{~km} / \mathrm{s}$ and $8.0 \mathrm{~km} / \mathrm{s}$, respectively. The high correlation seen at shallow $(20 \mathrm{~km})$ depth is probably an artifact of the inversion for large earthquakes (see CHRISTENSEN and RUFF, 1985). Therefore, the best estimate of point source depth is between $40-50 \mathrm{~km}$. The best double-couple mechanism reduced from the MTRFs for a depth of $40 \mathrm{~km}$ with a $P$-wave velocity of $6.7 \mathrm{~km} / \mathrm{s}$ is shown in Figure 4 (strike $238^{\circ}$, dip $23^{\circ}$, rake $82^{\circ}$ ). The strike of the trench in the epicentral region is $\mathrm{N} 55^{\circ} \mathrm{E}$ (Figure 5). We determined a single source time function from the re-inversion of the seismograms with a fixed double-couple mechanism obtained by the MTRF inversion. Figure 4 shows that the source time history consists of three stages: the initiation (duration $6 \mathrm{~s}$ ), the first pulse (duration $10 \mathrm{~s}$ and seismic moment $1.0 \times 10^{20} \mathrm{Nm}$ ), and the second pulse (duration $16 \mathrm{~s}$ and moment $1.7 \times 10^{20} \mathrm{Nm}$ ). Total seismic moment of $2.7 \times 10^{20} \mathrm{Nm}$ is similar to the result of the CMT inversion, $3.5 \times 10^{20} \mathrm{Nm}$.

\section{d) Aftershocks}

The solid circles in Figure 5 show the aftershock distribution within 2 days, according to PDE. They scatter in the depth range of $20-100 \mathrm{~km}$ and do not 


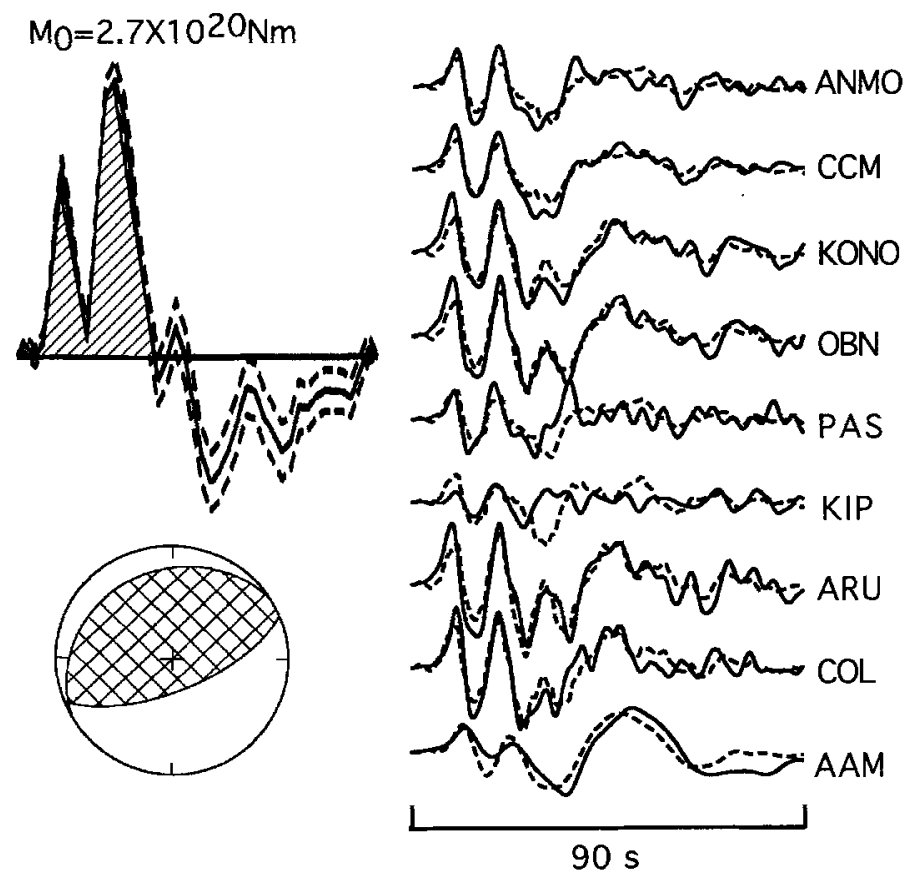

Figure 4

The result of the body wave inversion. The source time function is shown on the upper left. Seismic moment of $3.6 \times 10^{20} \mathrm{Nm}$ was released during the first $32 \mathrm{~s}$ (shaded region). The best double-couple mechanism is shown on the lower left. The observed (solid) and synthetic (dashed) seismograms with their station names are shown to the right. The time scale is the same for both the source time function and seismograms.

further identify the actual fault plane. We applied a master event relocation method for arrival time data at common stations for 10 large aftershocks to check the reliability of the epicenters. The result shows that the largest epicentral shift was $24 \mathrm{~km}$. The shifts of the other 9 were less than $7 \mathrm{~km}$. The relocated epicenters were very similar to the original PDE epicenters. As can be seen in Figure 5, the locations of aftershocks extend as far as $150 \mathrm{~km}$ along the trench axis.

\section{e) Ambiguity of Fault Plane}

Both surface wave and body wave analyses reveal that the best focal mechanism has one nodal plane dipping shallowly to the north and the other dipping steeply to the south. Although the strikes of the nodal plane from both analyses are slightly different, the slip direction is almost perpendicular to the Mariana trench. There are two possible explanations for this earthquake: one is an intraplate rupture due to slab pull; the other is an interplate underthrust event on a fault plane dipping to the north. If the former is the case, then the key feature is the steeply dipping tension axis, and the actual fault plane can be either of the two nodal planes which were 


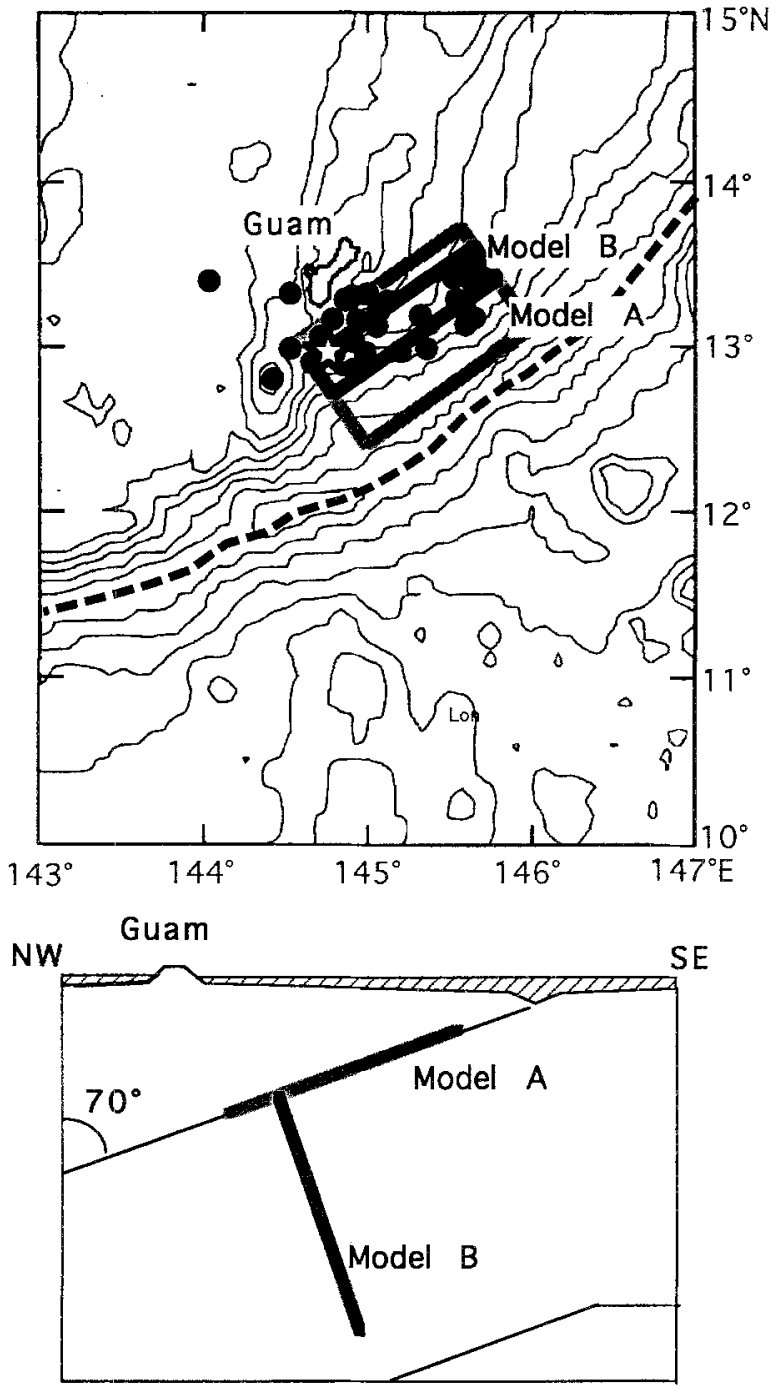

Figure 5

The location of the two fault models. Large and small rectangles show the location of fault models $\mathrm{A}$ and B, respectively. The star shows the epicenter of the 1993 Guam earthquake. The solid circles show the epicenters of aftershocks within 2 days, according to PDE. The dashed line represents the trench axis. Bottom part shows the vertical cross section of the two fault models in the northwest-southeast direction.

defined by the surface and body wave analyses. However, if the latter is the case, the actual fault plane has to be the shallow dipping plane. Identification of the actual fault plane is very important to understanding the source process of this earthquake. In the next section, we test the possibility of identifying the actual fault plane from the tsunami waveforms. 


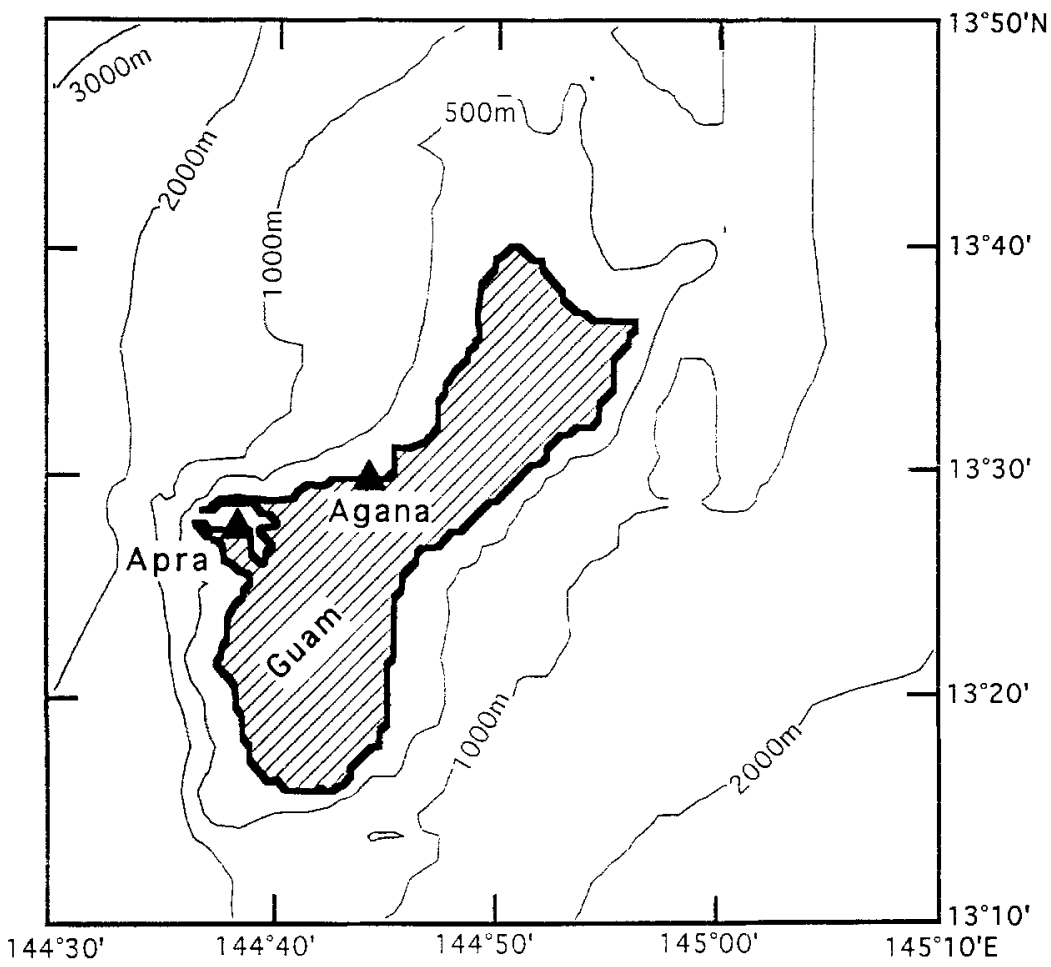

Figure 6

Bathymetry map around Guam Island. The triangles show the location of tide gauge stations, Apra and Agana.

\section{Tsunami Analysis}

\section{a) Tsunami Data}

Recently, several pressure gauges have been installed on the deep ocean bottom off the Japanese coast (OKADA, 1991). Records from one tide gauge and two ocean bottom pressure gauge stations near Japan are used as far-field tsunami waveform data. The location and name of these stations are shown in Figure 1. Records from two tide gauge stations in Guam Island are used as near-field tsunami waveform data. The location and name of these stations are shown in Figure 6. These records at Agana and Apra in Guam were sampled at a 15-min and 6-min interval, respectively.

\section{b) Computation of Tsunami}

The equation of motion and the equation of continuity for linear long waves are solved by a finite-difference method in the spherical coordinate system (HwANG et 
al., 1972; KowALIK and MURTY, 1984; SATAKE, 1995). We computed the far-field tsunami in the area shown in Figure 1. The grid spacing is 2 minutes. A finer grid system of 1 minute was used near Japan to incorporate the small-scale topography near tide gauge and ocean bottom pressure gauge stations. We also computed the near-field tsunami in the area shown in Figure 5 with a grid spacing of 20 seconds. The initial condition of tsunami propagation is an ocean bottom deformation, which is computed using OKADA's (1985) formulas.

\section{c) Effect of Fault Geometry on the Tsunami Waveform}

Based on the seismological analyses, we tested two different fault models. One model is a steeply-dipping fault to the south (fault model A) shown in Figure 5. The other fault model is a shallowly-dipping fault to the north (fault model B), also shown in Figure 5. The fault length of both models is $130 \mathrm{~km}$ and the down-dip width is $85 \mathrm{~km}$. Both fault models cover main shock epicenter and majority of the aftershock area. The average slip is estimated to be $0.8 \mathrm{~m}$ from the seismic moment of $3.5 \times 10^{20} \mathrm{Nm}$ obtained from the surface wave analysis, assuming a rigidity of $4 \times 10^{10} \mathrm{~N} / \mathrm{m}^{2}$.
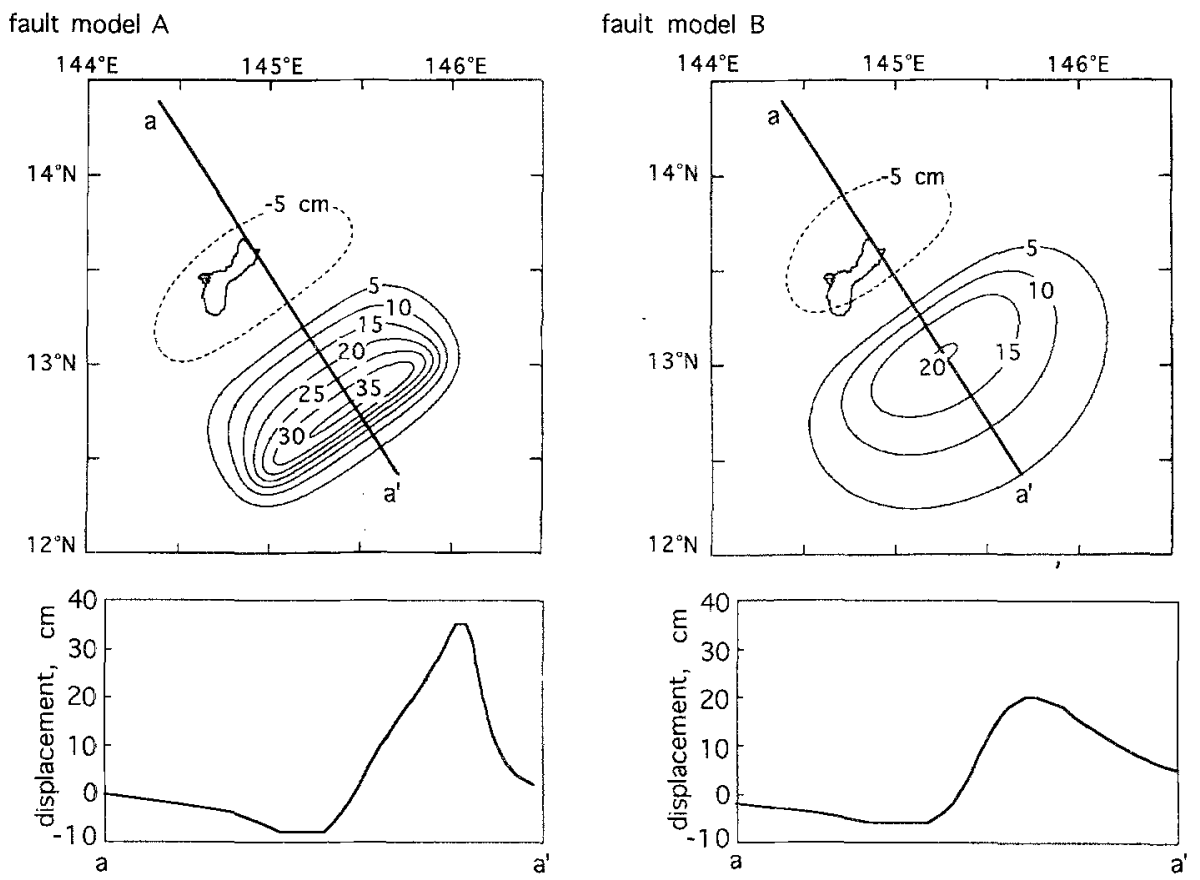

Figure 7

The vertical displacement of fault models $\mathrm{A}$ and $\mathrm{B}$. Bottom parts show the cross section of vertical displacements along a-a' line. 
a) Tide gauge

Mera

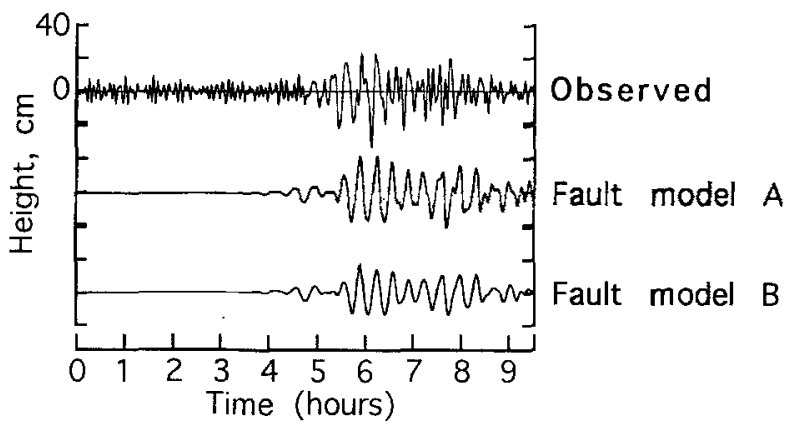

b) Ocean bottom pressure gauge

Boso-1
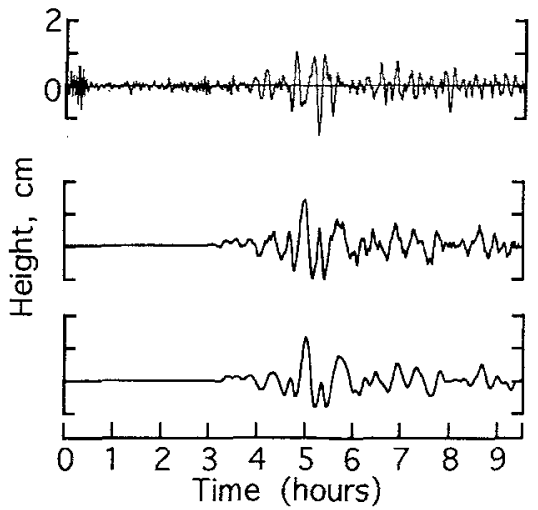

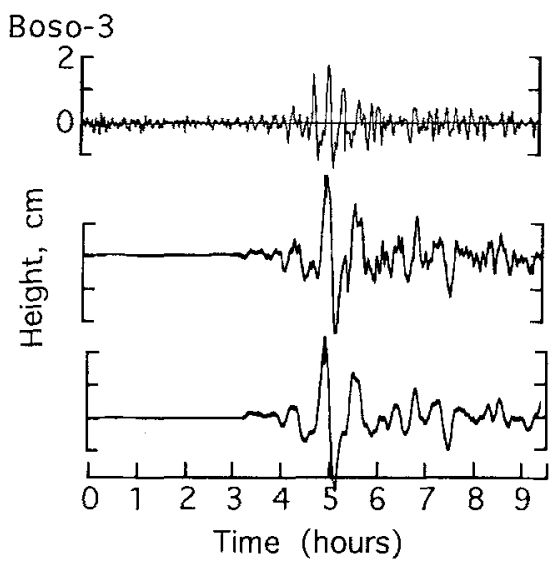

Figure 8

Comparison of the observed and computed tsunami waveforms from fault models $A$ and $B$ at a) the tide gauge at Mera, and b) two ocean bottom pressure gauges (Boso-1 and Boso-3).

The ocean bottom deformation calculated from the two different fault models is shown in Figure 7. It shows that the shape of the vertical deformation from the two fault models is different. The cross section of vertical deformation from fault model $\mathrm{A}$ in Figure 7 displays a sharp peak. However, the cross section of vertical deformation from fault B in Figure 7 shows a gentle peak. The deformation pattern for fault model B is much smoother than that for fault model $\mathrm{A}$. In other words, the deformation for fault model A contains shorter wavelength components than that for fault model $B$. These differences in the vertical deformation would probably cause differences in tsunami waveforms at the nearby tide gauge stations.

The waveform comparisons between fault models $\mathrm{A}$ and $\mathrm{B}$ are shown in Figures 8 and 9. The computed tsunami waveforms at Mera, Boso-1 and Boso-2 show no significant difference between fault models A and B (Figure 8). This indicates that 
(a) Agana

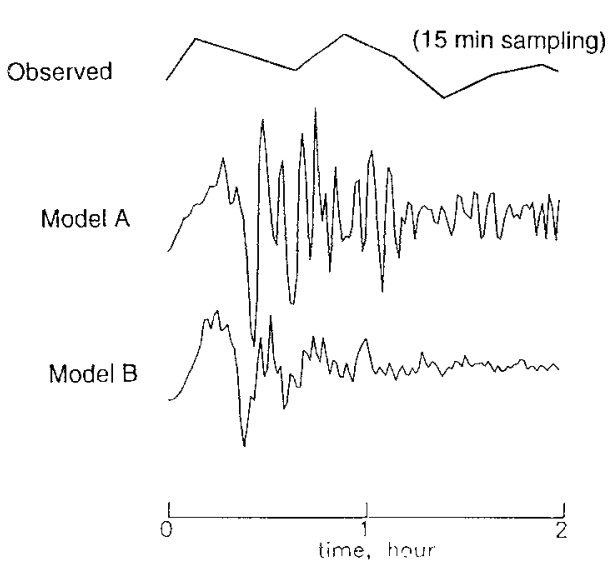

(b) Apra
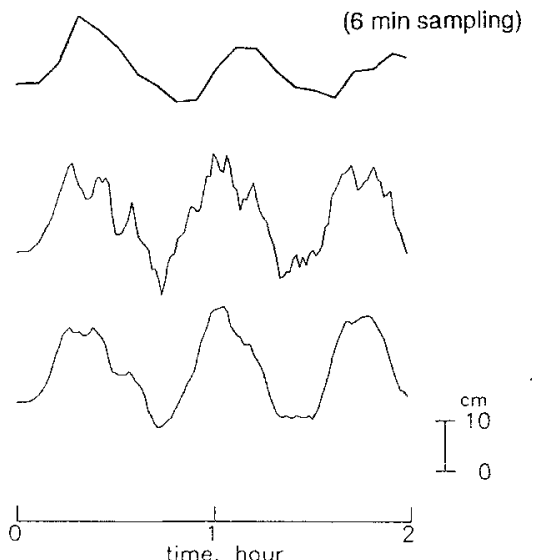

Figure 9

Comparison of the observed and computed tsunami waveforms from fault models $\mathrm{A}$ and $\mathrm{B}$ on two tide gauges at (a) Agana and (b) Apra in Guam. Computed tsunami are plotted using the sampling rate of 1 sample/min.

the far-field tsunami waveforms are not useful in identifying the actual fault plane for this particular case.

The computed tsunamis (Figure 9a) at Agana, Guam, using fault models A and $B$, show a small difference in the shape of the first pulse (first 15 min in Figure 9a). This probably corresponds to the difference in the vertical deformation shown in Figure 7 . We may be able to determine the actual fault plane from this difference. The computed waveform from fault model A displays high-frequency waves of larger amplitude than the computed waveform from fault model B (Figure 9a). These large, high-frequency waves are probably generated from the sharp peak at the southeast end of the vertical deformation from fault model A (Figure 7). This indicates that the near-field tsunami waveforms are useful for identifying the actual fault plane. Unfortunately, the observed data were sampled at $15 \mathrm{~min}$, causing a loss of information by aliasing (Figure 10a). The period of the high-frequency wave is about $5-6 \mathrm{~min}$; therefore, to identify the actual fault plane, the observed data should be sampled at 2 min or less.

A similar difference in high-frequency waves from two different models is also found for the Apra Harbor tide gauge record, although the amplitude of high-frequency waves is smaller than that in the Agana waveforms (Figure 9b). Unfortunately, as the observed data were sampled at $6 \mathrm{~min}$, the differences were lost by averaging and aliasing. Figure $10 \mathrm{~b}$ shows the same observed and the computed tsunamis which are resampled at $6 \mathrm{~min}$ with 3 min averages. The computed tsunamis in Figure 10b are almost identical. We could not obtain any information concerning the fault geometry from these observations. 
(a) Agana

Observed

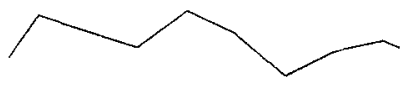

Model A

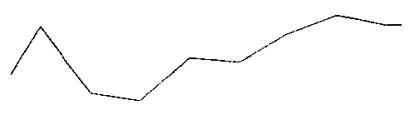

Model B

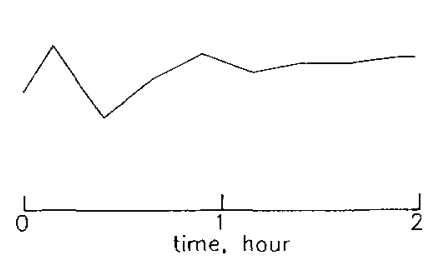

(b) Apra
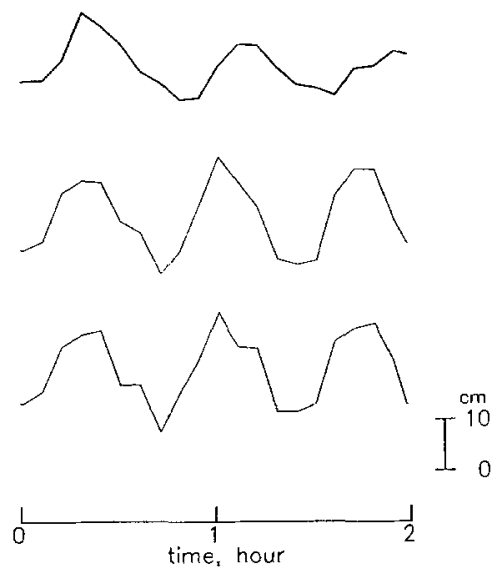

Figure 10

Comparison of the observed and computed tsunami waveforms from fault models $\mathrm{A}$ and $\mathrm{B}$ on two tide gauges at (a) Agana and (b) Apra. Computed waveforms are processed in the same way as the observed.

\section{d) Excitation of Tsunami}

The observed and computed waveforms fit well at the tide gauge and ocean bottom pressure gauge stations, except at Agana where the observed data are severely undersampled ( 1 sample/15 $\mathrm{min}$ ) (Figures 8 and 10). This indicates that both fault models provide a consistent explanation for both seismic and tsunami waves. SCHINDELE et al. (1995) categorized this event as a "tsunami-deficient" earthquake, on the basis of a spectral analysis of seismograms. Among the other tsunamigenic earthquakes on the Izu-Bonin-Mariana ridge system, the 1990 Mariana earthquake had a similar feature (SATAKE et al., 1992). But the 1984 Torishima earthquake was different; its tsunami excitation was considerably larger than expected from the seismic wave analysis (SATAKE and KANAMORI, 1991).

\section{e) Tsunami Propagation}

Figure 11 exhibits the snapshots of the tsunami propagation at $0,1,2$, and 3 hours after the origin time for fault model A. As can be seen in Figure 11, the large tsunamis travel slowly along the ridge system (Izu-Bonin-Mariana Ridge), and the tsunami energy is trapped by the ridge system. Figure 8 shows that the largest tsunami arrived at the tide gauge and ocean bottom pressure gauge at about one and a half hours after the first arrival (around 5 hours for Bosc-1 and 2, around 6 hours at Mera). This type of wave was also observed in the tsunami caused by the Mariana earthquake of April 5, $1990\left(M_{w}=7.3\right)$ and is called a ridge wave (SATAKE et al., 1992). 


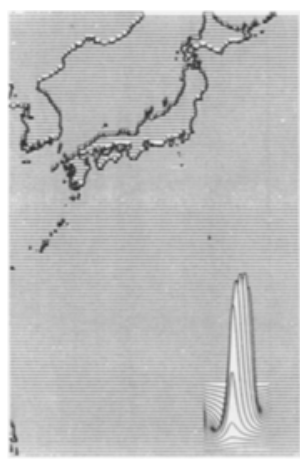

O hour

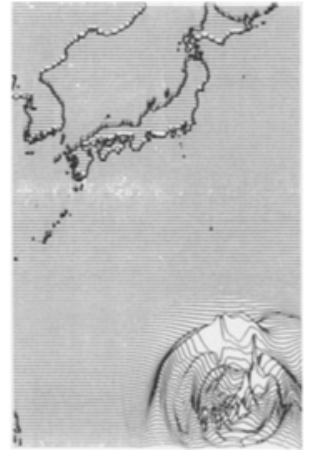

Thour

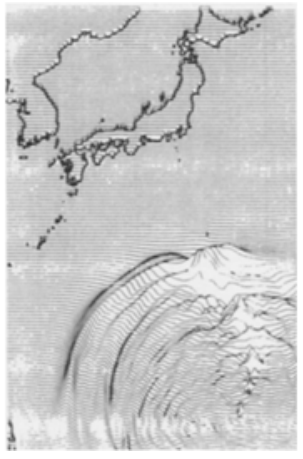

2hours

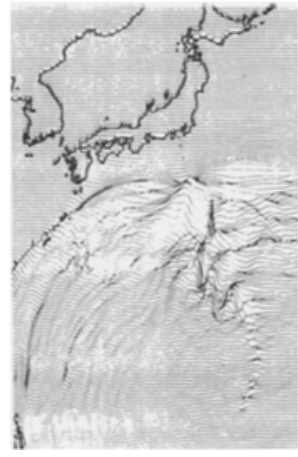

3hours

Figure 11

The snapshots of tsunami propagation at $0,1,2,3$ hours after the origin time of the earthquake.

\section{f) Effect of Grid Size on the Tsunami Waveform}

We compute the tsunami waveforms at the tide gauge station in Apra Harbor, Guam, both on the 1 minute and 20 second grid systems, and compare them with the observation (Figure 12). As can be seen in Figure 12, the computed waveforms are very different on the 1 minute and 20 second grid systems. The latter is closer to the observed waveforms. The period of the computed waveforms on the 1 minute grid system is much shorter than the period of the observed waveforms. This is

\section{Apra (model B)}
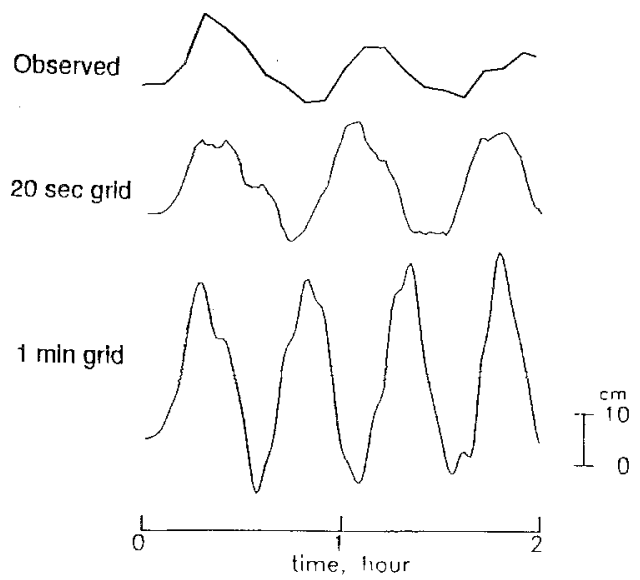

Figure 12

Comparison of the observed and computed tsunami waveforms using two grid systems, 1 minute and 20 seconds, on the tide gauge station at Apra. Fault model B is used for this comparison. 
a) 1 minute

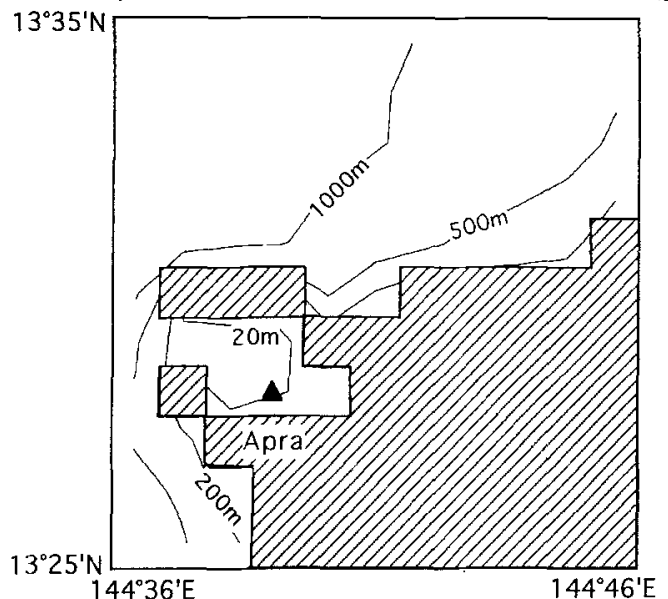

Figure 13 b) 20 second

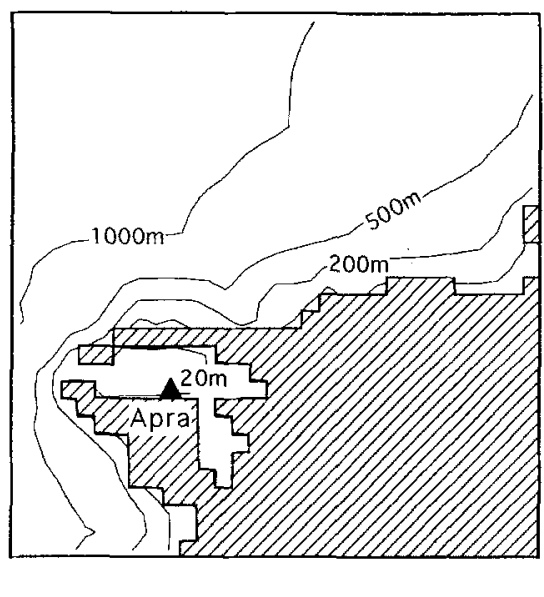

Grided bathymetry around Apra. a) 1-minute grid system, b) 20-second grid system.

because the 1-minute grid system cannot represent the coastal topography around Apra Harbor (Figure 13). The accuracy of the bathymetry is particularly important for computing the tsunami waveforms at tide gauge stations in a bay because the tsunami waveforms are largely controlled by the free oscillations of the bay.

\section{Discussion and Conclusion}

We have tried to determine the actual fault plane of the 1993 Guam earthquake. Our analysis of the seismic waves and aftershocks does not allow us to identify the fault plane. Thus we have investigated the possibility of identifying the actual fault plane from tsunami waveforms. The far-field tsunami waveforms at tide gauges or ocean bottom pressure gauges are not useful to identify the actual fault plane. The near-field tsunami waveforms at the tide gauge station just above the fault (about $60 \mathrm{~km}$ away from the epicenter) provide useful information for the identification of the actual fault plane of the earthquake, if the tsunami waveforms are sampled at least every $2 \mathrm{~min}$. Current sampling rates at these stations ( $6 \mathrm{~min}$ and $15 \mathrm{~min}$ ) are too coarse to make use of the near-field tsunamis for earthquake source study.

The dip of the shallow nodal plane is $17^{\circ}$ (CMT) to $23^{\circ}$ (MTRF), which is a typical underthrust dip angle found in other subduction zone. On the other hand, the $T$ axis dips about $65^{\circ}$ which is steeper than the apparent slab dip, about $40^{\circ}$. While this tectonic argument offers some preference for an underthrusting interpretation, it is not a proof of the actual fault plane. To resolve this question in the future, different data or qualitative tectonic arguments must be used. It is an important question to answer. 


\section{Acknowledgements}

We thank J. Johnson for helpful comments. The tide gauge and ocean bottom pressure gauge records in Japan were provided by Yoshinobu Tsuji at Earthquake Research Institute, Tokyo University and Masami Okada at Meteorological Research Institute in Japan. The tide gauge record at Agana, Guam was provided by Isao Matsuoka at USGS Water Resource Division. The tide gauge record at Apra Harbor, Guam was provided by Frank González at NOAA's Pacific Marine Environmental Laboratory. This work was supported by NSF (EAR 9117800).

\section{REFERENCES}

Christensen, D. H., and Ruff, L. J. (1985), Seismic Coupling and Outer Rise Earthquakes, J. Geophys. Res. 75, 1637-1656.

Dziewonski, A. M., Chou, T. A., and Woodhouse, J. H. (1981), Determination of Earthquake Source Parameters from Waveform Data for Studies of Global and Regional Seismicity, J. Geophys. Res. 86, $2825-2853$.

Fukushima, T., Suetsugu, D., Nakanishi, I., and Yamada, I. (1989), Moment Tensor Inversion for Near Earthquakes Using Long-period Digital Seismographs, J. Phys. Earth 37, 1-29.

Hwang, L.-S., Butler, H. L., and Divoky, D. J. (1972), Tsunami Model: Generation and Open-sea Characteristics, Bull. Seismol. Soc. Am. 62, 1579-1596.

Kowalik, Z., and Murty, T. (1984), Computation of Tsunami Amplitudes Resulting from a Predicted Major Earthquake in the Shumagin Seismic Gap, Geophys. Res. Lett. 11, 1243-1246.

OKADA, M., Ocean bottom pressure gauge for tsunami warning system in Japan. In Proc. 2nd UJNR Tsunami Workshop (eds. BrennAN, A. M., and LANDer, J. F.) (National Geophysical Data Center, Boulder, Colorado, USA 1991) pp. 219-227.

OKada, Y. (1985), Surface Deformation Due to Shear and Tensile Faults in a Half-space, Bull. Seismol. Soc. Am. 75, $1135-1154$.

Ruff, L. J., and Miller, A. D. (1994), Rupture Process of Large Earthquakes in the Northern Mexico Subduction Zone, Pure Appl. Geophys. 142, 101-172.

SATAKE, K. (1995), Linear and Non-linear Computations of the 1992 Nicaragua Earthquake Tsunamis, Pure Appl. Geophys., this issue.

Satake, K., and Kanamori, H. (1991), Abnormal Tsunamis Caused by the June 13, 1984, Torishima, Japan, Earthquake, J. Geophys. Res. 96, 19933-19939.

SATAKE, K., YoshidA, Y., and ABE, K. (1992), Tsunami from the Mariana Earthquake of April 5, 1990: Its Abnormal Propagation and Implications to Tsunami Potential from Outer-rise Earthquakes, Geophys. Res. Lett. 19, 301-304.

Shindele, F., Raymond, D., Gaucher, E., and OkAl, E. A. (1995), Analysis and Automatic Processing in Near Field of Eight 1992-1994 Tsunamigenic Earthquakes: Improvements Towards Real-time Tsunami Warning, Pure Appl. Geophys., this issue.

SIGRIST, D. J. (1995), Tsunamis in Guam, Tsunami Newsletter 27, 20.

Uyeda, S., and KANAMORI, H. (1979), Back-arc Opening and the Mode of Subduction, J. Geophys. Res. 84, 1049-1061.

YoshidA, Y., SATAKE, K., and ABE, K. (1992), The Large Normal-faulting Mariana Earthquake of April 15, 1990 in Uncoupled Subduction Zone, Geophys. Res. Lett. 19, 297-300. 